\title{
Plurilingüismo y formación de maestros indígenas en la Argentina
}

Virginia Unamuno Kaschapav

CONICET-Universidad de Buenos Aires, Argentina

\section{Introducción}

Argentina es uno de esos países que en general se asocia al monolingüismo ${ }^{1}$. Esto se debe a muchas razones, pero principalmente porque se trata de uno de los estados sudamericanos en los cuales su población tiene de origen europeo, mestizo y aborigen fue escolarizada a lo largo de su historia en una propuesta escolar lingüísticamente homogeniezante, a partir de la ley que a principios del siglo XX impuso el castellano como lengua única vehicular de contenidos en la educación pública.

Las diversas lenguas originarias de su actual territorio así como las numerosas lenguas llevadas allí por las migraciones históricas y contemporáneas han sido objeto de procesos de silenciamiento y no gozaban hasta hace poco de ningún tipo de reconocimiento particular en la legislación ni en las prácticas escolares concretas (Acuña 2002). Actualmente, gracias a la lucha de los pueblos originarios, a la circulación de un nuevo discurso en el cual el respeto de la diversidad lingüística es parte del respeto de los derechos humanos y al reconocimiento institucional (plasmado en la reforma constitucional de 1994 y la Ley federal de educación de 2006 que reconocen el derecho a una educación plurilingüe), pareciera haber indicios de un cambio en la visibilidad escolar de las lenguas diferentes al castellano en la Argentina, y de la emergencia de nuevas políticas para su protección.

Se calcula que son 12 o 13 las lenguas aborígenes que se hablan en la Argentina, si bien se sabe que antes de la llegada de los españoles se hablaban alrededor de 35 (Censabella 1999). La pérdida de las lenguas originarias está relacionada con diversos factores, entre los cuales hace falta mencionar el exterminio físico de sus hablantes, su desplazamiento hacia otras zonas por la fuerza y los procesos de ocultamiento de su conocimiento por parte de los propios hablantes como estrategia de supervivencia a los sistemas represivos estatales y privados sobre los pueblos originarios. En la memoria histórica de estos pueblos, el conocimiento de la lengua ha sido asociado con peligros y desventajas, ideas que han influido sin duda en el corte en la transmisión intergeneracional de estas lenguas. 
Según Censabella (2001), las lenguas de los pueblos originarios que aún se hablan en la Argentina son: toba, pilagá, mocoví, wichí, nivaclé, chorote, ava-chiriguano, mbya, guaraní, quichua santiagueño, mapudungun (o mapuche) y tehuelche.

Los problemas de denominación y clasificación, habituales en la descripción del multilingüismo en todo el mundo, también se encuentran en la Argentina (Censabella 2001). Lenguas diferentes son consideradas una sola por algunos, una sola lengua sirve para nombrar lenguas que para otros autores son diferentes. El siguiente cuadro, extraído de Messineo \& Cuneo (2006), ejemplifica la clasificación de las diferentes lenguas en la Argentina según familias lingüísticas.

Cuadro 1. Lenguas indígenas agrupadas en familias lingüísticas

\begin{tabular}{|c|c|}
\hline Lengua & Familia lingüística \\
\hline $\begin{array}{l}\text { quechua } \\
\text { quichua santiagueño }\end{array}$ & quechua \\
\hline $\begin{array}{l}\text { guaraní correntino / goyano } \\
\text { guaraní paraguayo / yopará } \\
\text { chiriguano-chané } \\
\text { mbyá }\end{array}$ & tupí-guaraní \\
\hline $\begin{array}{l}\text { wichí } \\
\text { chorote } \\
\text { nivaclé }\end{array}$ & mataguaya \\
\hline \begin{tabular}{|l} 
toba \\
mocoví \\
pilagá
\end{tabular} & guaycurú \\
\hline vilela & lule-vilela \\
\hline tehuelche & chon \\
\hline mapudungun & lengua aislada \\
\hline
\end{tabular}

Messineo \& Cuneo 2006:6

Como puede verse, una y otras autoras no coinciden en el número de lenguas y esto es común en la bibliografía de referencia. Así tampoco coincide la identificación de lenguas propuestas por lingüistas y las propuestas por las asociaciones indígenas. Estas últimas afirman que existen otras lenguas que si bien no son habladas cotidianamente por los miembros de las comunidades originarias, son patrimonio cultural de las mismas y deben considerarse y protegerse. Los datos estadísticos, obtenidos mediante una encuesta organizada por el Instituto de Asuntos Indígenas dependiente del Gobierno Nacional tampoco arroja resultados coincidentes (INAI/INDEC 2005). 
Cuadro 2. Datos estadísticos de las lenguas habladas

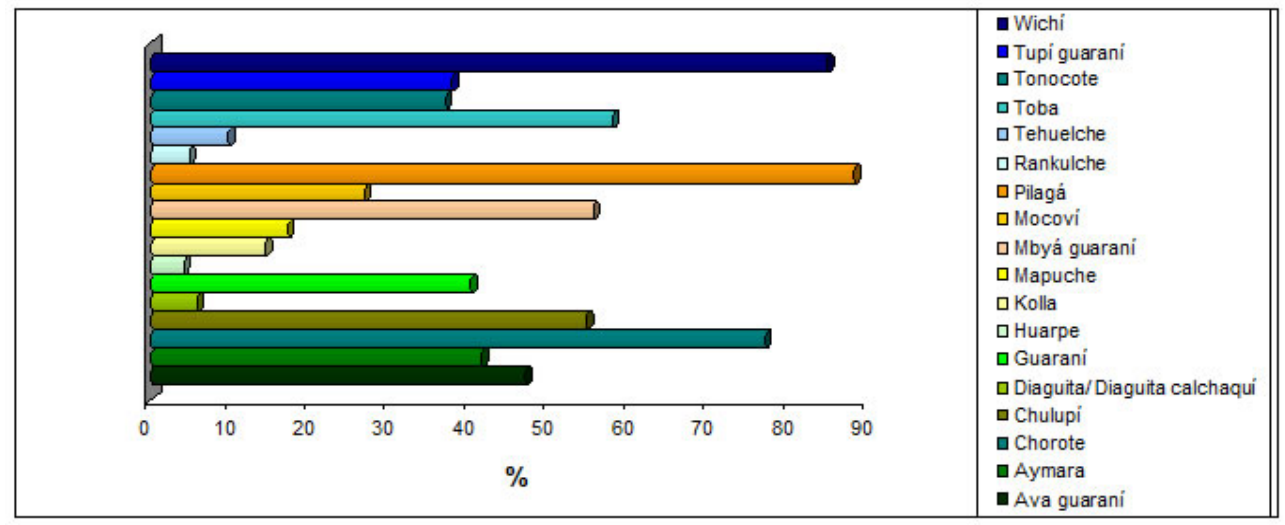

Fuente: INAI (a partir de la Encuesta Complementaria de Pueblos Indígenas 2004-2005, del Censo Nacional de Población, Hogares y Viviendas 2001, INDEC)

Más allá de estas clasificaciones y discordancias, lo que hace falta considerar es que se trata de un panorama complejo, caracterizado no sólo por una distribución desigual a lo largo del territorio argentino de dichas lenguas y de sus hablantes, sino también por situaciones sociolingüísticas muy diferentes. Así, entre estas lenguas, algunas son habladas por una comunidad muy pequeña y por un número muy minoritarios de personas (p.e. el tehuelche) y otras por una comunidad muy grande bilingüe, en la cual la mayoría de los hablantes emplean la lengua indígena para pocas situaciones de comunicación y no es en general transmitida intergeneracionalmente (p.e. el mapuche). Existen también otras lenguas que son símbolo de membresía comunitaria, son habladas por casi la totalidad de los miembros de la comunidad y transmitida de padres a hijos (p.e. el wichi), mientras que otras son empleadas sólo por algunos de sus miembros y en algunas de sus comunidades (p.e. el toba).

El panorama en general es confuso pero se caracteriza, rápidamente, por un bilingüismo o plurilingüismo (según la zona) extendido entre las comunidades originarias, marcado por el uso generalizado del castellano como lengua de escolarización, por el uso de esta lengua para resolver situaciones de comunicación con otros grupos sociales (llamados habitualmente criollos y blancos) y para los géneros verbales no propios de las situaciones cotidianas en las comunidades originarias. Cabe mencionar también que el castellano hablado por los indígenas (y criollos) goza de muy bajo prestigio (Acuña 2002). 


\section{La investigación}

Este es, a grandes rasgos, el contexto en el cual se inserta la investigación que llevamos a cabo en el norte de la Argentina, específicamente en la zona del Chaco, caracterizada por la presencia de numerosas lenguas y, en la actualidad, la región de más diversidad lingüística del país (Censabella 1999; 2001; 2005).

En el caso concreto de esta investigación, nos interesamos por estudiar la presencia de las lenguas aborígenes chaqueñas en la educación y, específicamente, por comprender el impacto de las nuevas políticas lingüísticas en la Argentina, favorables al reconocimiento del plurilingüísmo, en las prácticas lingüísticas escolares de la zona. Nuestra pregunta es la siguiente: ¿cuál es el impacto de la nueva política lingüística en la Argentina sobre la prácticas lingüísticas escolares en zonas plurlingües?

De esta gran pregunta, se desprenden otras que intentan

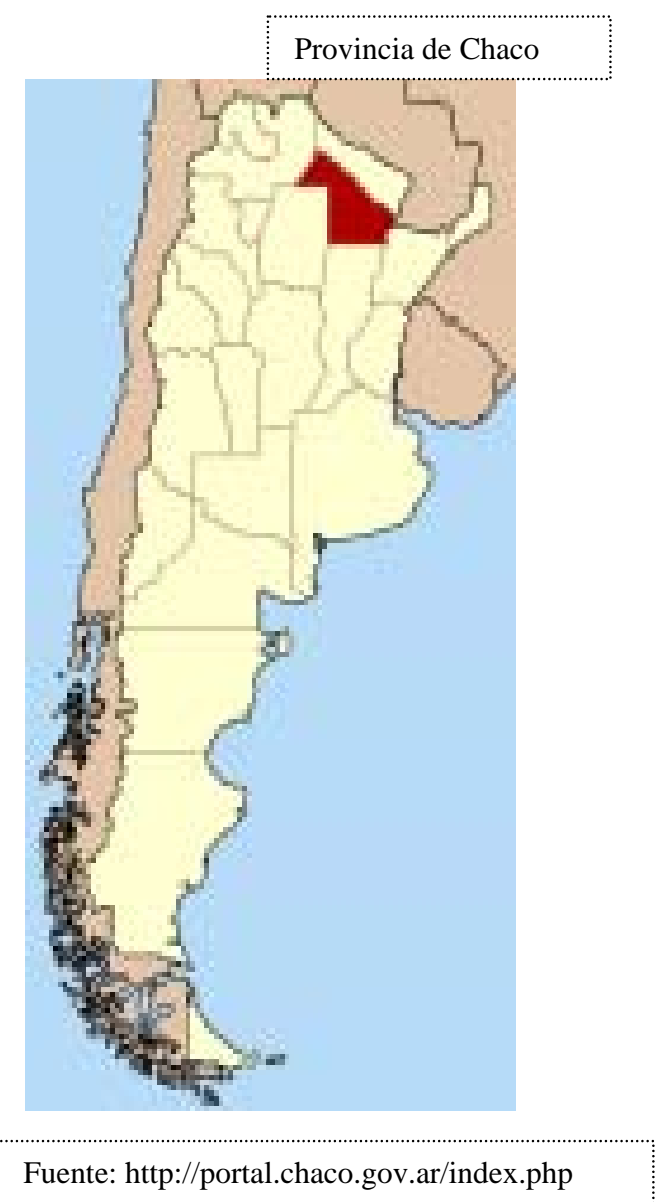
concretarlas: a. Dicha transformación política ¿comporta una trasformación real de las propuestas escolares (de monolingües a plurlingües)? b. las nuevas propuestas escolares derivadas del cambio legislativo ¿conllevan transformaciones en el orden sociolingüístico de las instituciones escolares y de su entorno?

Para intentar responder a estos interrogantes, consideramos importante: a. obtener elementos reales de la situación sociolingüística actual a través de un estudio de caso; b. hacer un estudio institucional sobre las dinámicas sociolingüísticas en que están involucradas los hablantes de las lenguas aborígenes.

Así, seleccionamos una población de la provincia del Chaco, denominada El Sauzalito, localizada en la zona llamada “El Impenetrable”, cuya población es mayoritariamente wichí y hablante de la lengua del mismo nombre. Allí, estamos realizando un estudio de carácter etnográfico cuya finalidad es dar cuenta de los usos y las representaciones de las lenguas castellana y wichí, así como de las dinámicas plurilingües que definen usos alterantes, superpuestos e híbridos de ambas lenguas. En esta población se encuentra también una de las sedes del primer instituto de educación terciaria dedicado específicamente a la formación de docentes aborígenes (CIFMA). La 
relación entre esta institución y su entorno (incluyendo a las escuelas de educación inicial y primaria de la zona) es el centro de interés de la presente investigación.

Si bien es cierto que esta investigación se inscribe en una sociolingüística aplicada a la educación, cabe considerar que, a diferencia de la mayoría de estudios sobre lenguas aborígenes dedicados a la descripción y clasificación tipológica de las mismas o a la recopilación y conservación de elementos verbales aislados y fuera de contexto-, este proyecto parte de la idea que las lenguas no son ajenas a los hablantes y a las relaciones sociales e históricas. Así, este estudio se inscribe en una perspectiva una perspectiva que a. pueda aportar elementos más allá de la retrato estático de las lenguas, b. considere la perspectiva de los actores en la descripción de las lenguas y de las dinámicas sociolingüísticas en que se encuentran involucradas; d. incluya visión humana sobre las lenguas, ligada a las prácticas culturales actuales, heterogéneas y cambiantes; e. que problematice la visión esencialista de las identidades; f. y que describa los cambios no sólo como “catástrofe”, sino como posibilidad de resistencia.

\section{Algunos primeros pasos}

Cuando uno se acerca a un terreno desconocido, cabe comenzar por una pregunta fundamental: ¿quién es quién? Esta pregunta deriva, normalmente, en un largo camino de escucha, de lectura, de recopilación de datos que permita a quien investiga acercarse a las formas de clasificación social que son propias de los miembros de la comunidad que se investiga. Por ello, la primera parte de la investigación consistió en estudiar las categorizaciones de los grupos sociales. En dicho estudio, el castellano emergió como un recurso clave de descripción in situ de las dinámicas sociales de la zona. Se trata, según muestran los datos, de un recurso de clasificación que se proyecta hacia competencias fundamentales para el acceso a la educación y, en el caso estudiado, para el acceso a los estudios terciarios que en el futuro permitirían a los jóvenes aborígenes convertirse en maestros para la modalidad intercultural bilingüe ${ }^{2}$.

Los siguientes fragmentos permiten observar cómo funciona esta clasificación así como algunas de sus consecuencias.

\section{Fragmento 1a}

“Entre ambas etnias, ente el criollo y wichí hay un diálogo común y sencillo para desarrollar el conocimiento...en cuanto salimos a fuera, nos sentimos perjudicados para dialogar con el mundo blanco"

\section{Fragmento 1b}




\begin{abstract}
Luis:
[...][12-17]y la po_ poca complicación que tengo sería hablar con con_una autoridadlpor ejemplo hablar con el intendentelusar esas palabras técnicas $\mid y$ y-| las palabras técnicas que aprendí será el los los respectol o sea como como tratar a - como hablar con una autoridad। por ejemplo decir_ usted o señor o donl cosa que en la calle lo _ en la calle hablo con mis compañeros \ pero - | puedo o digol chel o amigo nada másl| y la po_poca complicación que tengo sería hablar con con_ una autoridad por ejemplo hablar con el intendentel usar esas palabras técnicas $\mid y$ y-I las palabras técnicas que aprendí será el los los respectol o sea como como tratar a - como hablar con una autoridadl por ejemplo decir_ usted o señor o donl| cosa que en la calle lo _ en la calle hablo con mis compañeros chel o amigo nada másı|
\end{abstract}

En el primer fragmento, uno de los estudiantes del CIFMA opone criollos y wichis a otro mundo, el mundo de los blancos. Este mundo es el que es problemático y el que aparece en los datos sistemáticamente asociado a cierto uso del castellano que, en palabras de los estudiantes, podemos denominar "castellano de las palabras técnicas”. Según los datos, no se trata sólo de palabras propias de las disciplinas relativas a la educación, sino también, tal y como muestra el segundo fragmento, se trata de usos verbales ligados a situaciones asimétricas que colocan a los hablantes bilingües en cierta desventaja con respecto a los blancos, quienes en la zona, ocupan los lugares de poder (el médico, el intendente, el dueño de las tiendas, el director de la escuela, etc.). Por eso, Luis describe estas palabras como aquellas que son propias de situaciones formales -entre las cuales están las fórmulas de cortesía- que, según este estudiante, son difíciles de resolver. Este “castellano de las palabras técnicas” es el habla que los jóvenes wichís asocian al mundo blanco, un mundo que es descrito como ajeno y en el cual están claramente localizadas las instituciones escolares.

En el siguiente fragmento, José, estudiante del CIFMA, es entrevistado por una investigadora de Buenos Aires (capital de Argentina). Es interesante cómo en el inicio de esta entrevista, turno a turno, se describe a Ana como blanca, a través de una selección léxica particular, en la cual las palabras consideradas por los estudiantes como "técnicas" son empleadas de forma recurrente. 


\section{Fragmento 2:}

1. ana: josél ¿en qué año estás?|

2. josé: en tercer añol

3. ana: en tercer añol bien ya falta poquito para terminarl|

4. josé: exactamentel

5. ana: sí|¿¿y por qué estás estudiando acá en el cifma?|

6. josé: te explicoll yo siempre tuve una postura muy firmel|

7. ana:[afirma]

8. josé: considerando que soy aborígenl digamosıl| yo gracias a dios- este-\{(DC) incursioné muchísimo en el campo\}l podríamos decirlo asíl de la gente blancall y eh a los catorce añosl catorce quincel dieci nol dieciséis y diecisiete estuve en buenos aires। en quilmesl| para trabajar en casa de una familia rica y a la vez capacitarme en tornería de maderal y por culpa de eso perdí dos años de la escuelall y eh-|

9. ana: ¿y fueista allá a casa de parienteslo algo así?|

10. josé: nol terminé acá en yacarél un pueblito de los bajos de formosal y esa gente allí es privadol digamosl| y son gente evagelistal ¿cómo se dice?|

11. ana: ah sí sí| los hijos de beatríz -|miranda es el apellido/|tiene los chiquitos allí

12. josé: exactamentel|

13. ana> los más chiquitos\|

14. josé: exactamentel| cuando terminé séptimo grado ellos querían un muchacho para hacer practicar con ellos maderal y me llevaron a míl| y estuve dos años laburando y a la vez practicando la maderal y mi ideología se basa en lo siguientelyo siempre creo en la capacidad del hombrel| que se tiene que autosuperarsel| el hombre tiene que ganarse un lugarcitol| en el en la sociedadl| pero a la vez tenemos que poner el empeño nosotros para ganar el lugarl| pasa por nosotrosl| y lamentablemente le inculcaron una ideología alrevés】 hacia la comunidad aborígenl|

La lectura minuciosa de este fragmento permite observar que si bien Ana intenta orientar la entrevista hacia una situación informal (obsérvese el uso de los diminutivos, por ejemplo), José apela constantemente a recursos verbales y no verbales (p.e. el cambio de ritmo de frase) para describirla como una situación claramente asimétrica, que podríamos glosar como "conversación con blancos”. Asimismo, a lo largo de la entrevista, José coloca la interacción hacia el polo exolingüe (Py 1995), cuestionando la simetría entre ambos interlocutores respecto a la competencia en la lengua en que se desarrolla (p.e. en el turno 10, la pregunta “cómo se dice?).

Si bien podría considerarse desde otras perspectivas que José muestra cierta inseguridad lingüística, desde una perspectiva socialmente situada, podemos observar cómo interaccionalmente se describe al interlocutor y a la actividad que se lleva a cabo (Mondada 2000), inscribiendo esto que ambos están haciendo en la historicidad propia de los intercambios entre indígenas y blancos, entre grupos dominados y dominados. Porque en estas descripciones que se hacen en la práctica no dejan de resonar historias terribles de constante marginación de los grupos indígenas de las instancias de poder (como los estudios superiores y la docencia). Más aún si recuperamos la historia de control que ejercen los blancos sobre el lenguaje, evaluando en diferentes instancias cuál es el castellano correcto y cuál es el castellano adecuado para la actividad escolar. La lengua es recurso y es metáfora, así como la conversación es aquí y ahora, y también está anclada en la temporalidad evocada (o encubierta - Blommaert 2005:130).

El trabajo de campo en la zona y el relevamiento de diferentes tipos de datos (a través de entrevistas, charlas informales, cuestionarios, registros de clase, etc.) permiten relacionar estas 
descripciones con otras que también realizan miembros de la comunidad. Nos referimos, específicamente, a las autoridades y a algunos docentes de la zona que consideran que los jóvenes wichis no podrán ejercer plenamente la docencia en las escuelas de la zona "a pesar de hablar la lengua de los chicos”, porque “al ser tan silenciosos” no podrán controlar la disciplina de la clase, y, especialmente, porque no son suficientemente competentes en castellano. Pero también se relacionan con las narraciones de las primeras experiencias de los nuevos maestros bilingües en las escuelas de tradición monolingüe y de perspectiva blanca de la zona. Estas narrativas describen la experiencia de los primeros maestros a través de situaciones caracterizadas por la marginación y la subestimación por parte de directivos y colegas, que, incluso, se concretan en la imposibilidad de ejercer realmente como maestros bilingües, para lo cual han estado preparados durante cuatro años.

El “castellano de las palabras técnicas” aparece así como un elemento clave en la comprensión de la relación entre blancos y jóvenes indígenas, los cuales, si terminan la carrera, podrán ocupar un lugar profesional y en la escala social que tradicionalmente ocuparon sólo los blancos, quienes hasta ahora han sido los únicos que han accedido a una educación superior. Exclusividad que parece hoy estar cuestionándose.

\section{Conclusión}

En este breve artículo, sólo se pretendía sintetizar la intervención hecha en el marco del doctorado en didáctica de la lengua y de la literatura de la Universidad Autónoma de Barcelona. Se trata, como se ha notado, de una investigación que recién se inicia. Sin embargo, puede ser interesante poner en discusión algunos elementos para poder ir hacia delante. Es, así, una invitación para el debate.

En este sentido, parece importante comenzar a pensar en estudios sobre lenguas aborígenes americanas que vayan más allá de la descripción, la clasificación y la conservación. Si bien es cierto que los discursos conservacionistas sobre las lenguas y los discursos esencialistas sobre las culturas han sido y son empleados para alertar sobre las consecuencias nefatas de la homogeneización lingüística y cultual, cabe preguntarse hasta qué punto no son artefactos contraproducentes en el sentido que pueden ocultar relaciones más complejas y dinámicas más profundas en la relación entre lengua, identidades y diversidad. Esto sin negar que para los grupos minoritarios no sea este discurso uno de los pocas vías que ha dejado el poder para hacerse escuchar.

Ahora bien, las dinámicas sociales en que se inscribe el plurilingüismo y la educación necesitan también ser comprendidas en otras dimensiones. Este estudio, en principio, está 
mostrando que existe una distancia clave entre los discursos proteccionistas recogidos en la legislación y las políticas educativas en la Argentina y las prácticas plurilingües concretas. La viabilidad de la educación intercultural bilingüe en contexto aborigen parece no sólo depender de la posibilidad de contar con materiales, infraestructura o docentes que puedan hablar las lenguas de los pueblos originarios: se necesita de una transformación interna institucional y social en la cual el uso de dichos materiales y de dicha infraestructura se inscriba en una línea transformadora, y en el cual dichos docentes puedan ejercer el derecho de educar soberanamente. La descripción de las dinámicas sociolingüísticas pretende aportar al debate para que esto sea posible.

\section{Referencias bibliográficas}

Acuña, L. (2002) De la castellanización a la educación intercultural bilingüe: sobre la atención de la diversidad lingüística en la Argentina. Revista de historia bonaerense IX, 24: 47-52.

Blommaert, J. (2005) Discourse. Cambridge:Cambridge University Press.

Censabella, M. (1999) Las lenguas indígenas de la Argentina. Una mirada actual. Buenos Aires: Eudeba.

Censabella, M. (2001) Las lenguas indígenas del Chaco meridional y nordeste argentino Localización, vitalidad y prioridades de investigación - Trabajo publicado en Folia Histórica del Nordeste $\mathrm{n}^{\circ}$ 15, Resistencia (2001-2002): Instituto de Investigaciones Geohistóricas - Conicet, pp. 71-85.

Censabella, M. (2005) La revitalización de las lenguas y la educación bilingüe intercultural, Ponencia leída en el V Encuentro de Lenguas Aborígenes y Extranjeras, Dpto. de Lenguas Modernas. UNLP.

Messineo, C. y Cuneo, P. (2006) Las lenguas indígenas de la Argentina. Situación actual e nvestigaciones, Third International Workshop on (Semi) Numerical Techniques in Polynomial Equation Solving, in Honor of Joos Heintz's 60 ${ }^{\text {th }}, 2005$.

Mondada, L. (2000) La compétence de catégorisation: procédés situés de catégorisation des ressources linguistiques. La notion de contact de langues en didactique éd. par Pierre Martinez \& S. Pekarek Doehler, 81-102. Paris: ENS Editions \& Didier Erudition

Py, B. (1995) Quelques remarques sur les notions d'exolinguisme et de bilinguisme, Cahiers de Praxematique, 25, 79-95. Versió en català publicada a Articles de Didàctica de la Llengua i de la Literatura, 8 (1996).

INAI/INDEC (2005) Encuesta Complementaria de Pueblos Indígenas 2004-2005, del Censo Nacional de Población, Hogares y Viviendas 2001, INDEC. Disponible en: http://www.desarrollosocial.gov.ar/INAI/site/estadistica/estadistica.asp $\quad(1$ de julio de 2010). 


\section{Referencia de la autora:}

Virginia Unamuno es doctora en Filologia por la Universidad de Barcelona. Ha trabajado durante diez años en la Universidad Autónoma de Barcelona sobre temas de plurilingüismo y educación. Actualmente, esta realizando investigación sobre lenguas en contacto y educación bilingüe en el Norte de Argentina (CONICET-Universidad de Buenos Aires). Sus lineas de investigación son la sociolingüística y la enseñanza de lenguas en contextos de diversidad sociocultural. Es miembro del grupo de investigación GREIP (UAB).

Email: virginia.unamuno@uab.cat

1 NB (Editora): Este artículo procede del seminario sobre "Plurilingüismo y Formación de Maestros Indígenas en Argentina”, impartido por la Dra Virginia Unamuno el 28 de abril de 2010 en la Universidad Autónoma de Barcelona, organizado por el Máster Oficial de Investigación y el programa de Estudios Doctorales en Didáctica de la Lengua y la Literatura.

${ }^{2}$ En Argentina existen diversas modalidades educativas entre las cuales está la Educación Intercultural Bilingüe (EIB). Las escuelas según su población, localización y recursos puede solicitar su consideración como tal, lo que comporta recursos materiales y humanos particulares. Si bien existes lineamientos generales sobre su modalidad curricular, aún se está discutiendo la manera de aplicarlos. 